\title{
Afatinib as First-Line Treatment in Asian Patients with EGFR Mutation-Positive NSCLC: A Narrative Review of Real-World Evidence
}

\author{
Shun Lu (D) · Jin-Yuan Shih • Tae-Won Jang • Chong-Kin Liam • \\ Yongfeng Yu
}

Received: January 19, 2021 / Accepted: March 3, 2021 / Published online: March 17, 2021

(c) The Author(s) 2021

\begin{abstract}
Epidermal growth factor receptor tyrosine kinase inhibitors (EGFR TKIs) are a standard of care in the first-line treatment of patients with EGFR mutation-positive metastatic non-smallcell lung cancer (NSCLC). EGFR mutations are relatively common in Asian patients with NSCLC, and there is an increasing number of studies supporting the effectiveness of the second-generation TKI afatinib in routine clinical practice in Asia. This article reviews these realworld studies investigating afatinib as first-line treatment for EGFR mutation-positive NSCLC in Asian patients. Evidence from real-world studies with afatinib in this patient population supports findings from randomized controlled trials (RCTs) showing that afatinib is associated
\end{abstract}

\footnotetext{
S. Lu $(\bowtie) \cdot$ Y. Yu

Shanghai Lung Cancer Center, Shanghai Chest

Hospital, Shanghai Jiaotong University, 159

Tianzhou Road, Shanghai 200030, China

e-mail: shunlu@sjtu.edu.cn

J.-Y. Shih

Department of Internal Medicine, National Taiwan

University Hospital, Taipei, Taiwan

T.-W. Jang

Department of Internal Medicine, Kosin University

Gospel Hospital, Busan, South Korea

C.-K. Liam

Department of Medicine, Faculty of Medicine,

University of Malaya, Kuala Lumpur, Malaysia
}

with more favorable outcomes compared with the first-generation EGFR TKIs. The effectiveness of afatinib has also been shown in realworld studies in Asian patients with poor prognostic factors, who are often under-represented or excluded from RCTs, such as those with uncommon EGFR mutations, brain metastases, or poor performance status, and elderly patients. The tolerability profile of afatinib in the real-world setting reflects that seen in RCTs, with no new safety signals reported in realworld studies in Asian patients with EGFR mutation-positive NSCLC. Dose-modification strategies also seem to be effective in the real world, with results of the RealGido study, which included 44\% Asian patients, confirming findings from prospective clinical trials showing that tolerability-guided afatinib dose modifications can reduce the incidence of adverse events without adversely affecting clinical outcomes. While further research, including clinical trial data, is needed, real-world data have also demonstrated the feasibility of sequential afatinib followed by the third-generation TKI osimertinib in T790M-positive EGFR mutationpositive patients, which showed longer overall survival. Together, these real-world results demonstrate the real-world clinical effectiveness of afatinib as first-line treatment for patients with EGFR mutation-positive NSCLC. 


\section{PLAIN LANGUAGE SUMMARY}

Some patients with non-small-cell lung cancer (NSCLC) have a mutation in the EGFR gene, whose normal function is to regulate cell division. The proportion of NSCLC patients with these EGFR mutations is particularly high in Asian populations. Treatment of patients with EGFR mutation-positive NSCLC has changed markedly in recent years following the development of drugs called EGFR tyrosine kinase inhibitors (TKIs). Several EGFR TKIs have been developed, and clinical trial data have shown that the second-generation TKI afatinib and the third-generation TKI osimertinib are more effective than the first-generation TKIs erlotinib and gefitinib. However, these clinical trials, known as randomized controlled trials (RCTs), are highly selective, and many patients, such as elderly patients or those in poor health and/or with underlying diseases, are excluded. Consequently, less is known about how well TKIs work in these patients. Therefore, other less-selective studies, known as observational or 'realworld' studies, are used to provide information on the safety and effectiveness of EGFR TKIs across all patient groups seen in the clinic, not just those included in RCTs. In this article, we review the real-world evidence for the TKI afatinib as a treatment for Asian patients with EGFR mutation-positive NSCLC. Evidence from these real-world studies confirms that afatinib is more effective than erlotinib and gefitinib in real-world patients in Asia. Importantly, the efficacy and safety of afatinib is seen in groups of Asian patients often excluded from clinical trials including the elderly, those with brain metastases, and frail patients or those with other underlying diseases. Importantly, the safety profile of afatinib was similar to that seen in RCTs, and no additional side effects were identified in real-world patients. Also, importantly, real-world studies show that side effects can be effectively controlled by reducing the dose of afatinib. Real-world studies have also been used to demonstrate the feasibility and effectiveness of the sequential use of EGFR TKIs, particularly in Asian patients.
Keywords: Afatinib; Asian patients; Epidermal growth factor receptor; Non-small-cell lung cancer; Real-world evidence; Tyrosine kinase inhibitor

\section{Key Summary Points}

Epidermal growth factor receptor tyrosine kinase inhibitors (EGFR TKIs) are the standard of care for patients with EGFR mutation-positive non-small-cell lung cancer.

Less is known about the effectiveness of EGFR TKIs in patients often excluded from randomized controlled trials.

Observational data can demonstrate clinical effectiveness in these real-world patients.

Real-world evidence demonstrates the effectiveness of afatinib in Asian patients.

\section{DIGITAL FEATURES}

This article is published with digital features, including a summary slide and plain language summary, to facilitate understanding of the article. To view digital features for this article, go to https://doi.org/10.6084/m9.figshare. 14141273.

\section{INTRODUCTION}

The prevalence of epidermal growth factor receptor $(E G F R)$ mutations in patients with nonsmall-cell lung cancer (NSCLC) is relatively high in Asian populations compared with non-Asian populations [1-4]. For example, in a large, global meta-analysis of 456 studies, while the overall pooled prevalence for EGFR mutations 
was $32.3 \%$, the prevalence was only $14.1 \%$ in Europe but $50.2 \%$ in China [2]. Further, a study in south-west China reported a prevalence of $48.7 \%$ [5].

First-line use of EGFR tyrosine kinase inhibitors (TKIs) is a standard of care in EGFR mutation-positive metastatic NSCLC, both globally and in Asia [6-8]. Three generations of EGFR TKIs are available for the treatment of EGFR mutation-positive NSCLC, including the first-generation EGFR TKIs erlotinib and gefitinib (and icotinib in China), the second-generation ErbB family blockers afatinib and dacomitinib, and the third-generation EGFR TKIs osimertinib, as well as, for second-line therapy in South Korea, olmutinib, and in China, almonertinib. Except for olmutinib and almonertinib, all these EGFR TKIs have demonstrated significant improvements in progression-free survival (PFS) compared with the previous standard-of-care, platinum-based chemotherapy, in Phase 3 trials in patients with EGFR mutation-positive NSCLC [9-19]. Secondand third-generation TKIs have also demonstrated superior outcomes versus the first-generation TKIs, erlotinib and gefitinib $[16,17,20,21]$. However, no prospective headto-head studies have yet compared second- and third-generation agents.

While randomized controlled trials (RCTs) are clearly necessary to demonstrate treatment efficacy and safety, their 'external validity' or generalizability to broader patient populations seen in routine clinical practice may be limited. For example, RCTs generally have strict inclusion and exclusion criteria, as well as design features such as discontinuation criteria based on Response Evaluation Criteria In Solid Tumors (RECIST) assessments that may not reflect clinical practice where patients often continue treatment beyond radiological progression. It is therefore important to complement data from clinical trials with evidence from observational studies that reflect realworld clinical practice and include patient populations who would typically not be included in a clinical trial, such as elderly patients and those with poor performance status or other less favorable prognostic factors (e.g., uncommon EGFR mutations, brain metastases, comorbidities) [22-24]. As such, there is increasing recognition of the value of real-world evidence, including by, for example, the US Food and Drug Administration and the American Society of Clinical Oncology (ASCO) $[22,24,25]$, as well as regulatory bodies in Asian countries [26].

There is an increasing number of studies supporting the safety and effectiveness of afatinib in real-world patient populations, particularly in Asian patients. This is in contrast to other second- and third-generation EGFR TKIs, such as dacomitinib and osimertinib [27], for which substantially less real-world evidence is available, possibly due, at least in part, to their more recent regulatory approvals. As the vast majority of real-world evidence in Asian patients with EGFR mutation-positive NSCLC is for afatinib, we therefore performed a literature review of real-world studies that have assessed afatinib as first-line treatment for EGFR mutation-positive NSCLC in Asian patients. We searched PubMed and EMBASE (up to 10 January 2020) and the most recent abstract databases of major oncology meetings [ASCO, European Society for Medical Oncology (ESMO), ESMO Asia, and World Conference on Lung Cancer] with the following search terms: ('afatinib' or 'EGFR TKI') and ('Asian') and ('retrospective' or 'real-world' or 'expanded-access' or 'single-center' or 'elderly' or 'brain metastases' or 'uncommon EGFR mutation'). For this narrative review, articles identified from the database searches were selected based on their potential relevance to the topic of this review, focusing on clinical outcomes with afatinib in the diverse Asian populations seen in real-world clinical practice. Reference lists of the selected articles were also checked for additional potentially contributory references. This article is based on previously conducted studies and does not contain any studies with human participants or animals performed by any of the authors. 
Table 1 Real-world studies conducted in Asia comparing afatinib with first-generation EGFR TKIs in EGFR mutationpositive NSCLC: summary of results for the overall study population

\begin{tabular}{|c|c|c|c|c|}
\hline Study & Treatment & Patients $(n)$ & Clinical outcome (months) & $p$ value $^{\mathrm{a}}$ \\
\hline \multicolumn{5}{|l|}{ Japan } \\
\hline \multirow[t]{3}{*}{ Fujiwara et al. [28] } & Afatinib & 28 & TTF: 13.1 & \\
\hline & Gefitinib & 83 & TTF: 9.2 & 0.123 \\
\hline & Erlotinib & 36 & TTF: 9.8 & 0.795 \\
\hline \multirow[t]{3}{*}{ Ito et al. [29] } & Afatinib & 215 & OS: 38.6 & $0.0031^{\mathrm{b}}$ \\
\hline & Gefitinib & 726 & OS (gefitinib and erlotinib combined): 30.9 & \\
\hline & Erlotinib & 413 & & \\
\hline \multicolumn{5}{|l|}{ South Korea } \\
\hline \multirow[t]{3}{*}{ Kim et al. [30] } & Afatinib & 165 & PFS: 19.1 & 0.001 \\
\hline & Gefitinib & 230 & PFS: 13.7 & \\
\hline & Erlotinib & 72 & PFS: 14.0 & \\
\hline \multicolumn{5}{|l|}{ Taiwan } \\
\hline \multirow[t]{3}{*}{ Kuan et al. [31] } & Afatinib & 81 & PFS: not reached & \\
\hline & Gefitinib & 304 & PFS: 11.4 & $<0.001$ \\
\hline & Erlotinib & 63 & PFS: not reached & \\
\hline \multirow[t]{3}{*}{ Lin et al. [32] } & Afatinib & 99 & PFS: 12.4 & 0.67 \\
\hline & Gefitinib & 134 & PFS: 12.4 & \\
\hline & Erlotinib & 68 & PFS: 14.4 & \\
\hline \multirow[t]{3}{*}{ Su et al. [33] } & Afatinib & 99 & PFS: 16.1 & $<0.001$ \\
\hline & Gefitinib & 534 & PFS: 11.5 & \\
\hline & Erlotinib & 220 & PFS: 11.7 & \\
\hline \multirow[t]{3}{*}{ Tu et al. [34] } & Afatinib & 104 & PFS: 12.2 & \\
\hline & Gefitinib & 195 & PFS: 9.8 & 0.035 \\
\hline & Erlotinib & 123 & PFS: 11.4 & 0.38 \\
\hline
\end{tabular}

$E G F R$ epidermal growth factor receptor, IPTW inverse probability treatment weighting, NSCLC non-small cell lung cancer, $O S$ overall survival, $P F S$ progression-free survival, TKIs tyrosine kinase inhibitors, TTF time to treatment failure ${ }^{a}$ Afatinib versus comparator(s)

${ }^{\mathrm{b}}$ Unadjusted $p$ value $=0.0031 ; p<0.0001$ when adjusted by IPTW 


\section{REAL-WORLD EVIDENCE FOR THE EFFECTIVENESS OF AFATINIB}

\section{Effectiveness in General, Asian Real-World NSCLC Populations}

Evidence from real-world studies on the effectiveness of afatinib among Asian patients supports the prospective clinical trial data on the efficacy of afatinib in patients with EGFR mutation-positive NSCLC. As seen in RCTs, realworld evidence indicates that afatinib is associated with more favorable outcomes versus the first-generation EGFR TKIs in real-world Asian patient populations (Table 1).

Several real-world studies conducted in Asian countries have compared clinical outcomes with afatinib versus first-generation EGFR TKIs in EGFR mutation-positive NSCLC, including studies conducted in Japan [28, 29], South Korea [30], and Taiwan [31-34] (Table 1). Key clinical outcomes [PFS, overall survival (OS), time to treatment failure (TTF)] were numerically, and, in many cases, significantly, greater with afatinib than with gefitinib and/or erlotinib across these comparative studies [28-31, 33, 34]. For example, in the South Korean study, median PFS was 19.1 months with afatinib compared with 13.7 and 14.0 months with gefitinib and erlotinib, respectively ( $p=0.001$ for both comparisons) [30]. One exception was a study conducted in Taiwan, in which median PFS of 12.4, 12.4, and 12.6 months were reported for afatinib, gefitinib, and erlotinib, respectively $(p=0.67)$ [32].

This evidence is supported by results from various other non-comparative real-world studies with afatinib in Asian patients with EGFR mutation-positive NSCLC. In an analysis of 85 patients in Malaysia, afatinib was also an effective first-line treatment for patients with EGFR mutation-positive NSCLC, with an objective response rate (ORR) of $76.5 \%$, disease control rate of $95.3 \%$, and median PFS of 14.2 months $[95 \%$ confidence interval (CI) 11.85-16.55] [35]. In an analysis of 140 patients in Taiwan, the ORR with first-line afatinib was $67.2 \%$ and median PFS was 11.8 months [36]. In an analysis of 76 patients in Japan who received afatinib in the first-line setting, median PFS was 17.8 months (95\% CI 13.7-21.5) [37]. As might be expected, median PFS was substantially longer in the first-line than the second-line setting: median PFS was 8.0 months (95\% CI 4.9-9.5 months) in 52 patients who received afatinib after failure of a first-generation EGFR TKI [37]. Similarly, a Chinese study included 39 patients treated in the first-line setting and 21 patients who received afatinib as second- or later-line therapy. As first-line therapy, afatinib was associated with a median PFS of 12.3 months (95\% CI 7.6-17.0) in the overall population and 15.6 months (95\% CI 9.5-21.8) in patients with the common mutations Del19 or L858R. Median PFS in the first-line setting among patients treated with an initial dose of afatinib $40 \mathrm{mg} /$ day $(n=29) \quad$ or $30 \mathrm{mg} /$ day $(n=10) \quad$ was $14.5 \quad(95 \%$ CI $9.4-19.7)$ and 5.2 months (95\% CI $0.8-9.6)$, respectively $(p=0.101)$, whereas, second- or later-line treatment with afatinib at these starting doses was associated with median PFS of $3.0(n=12$, 95\% CI 1.3-4.8) and $5.0(n=9,95 \%$ CI $2.5-7.5)$ months, respectively $(p=0.375)[27,38]$. Similar outcomes were reported in another realworld study in China; in 88 patients who received first-line afatinib, median PFS was 14.2 months [39].

Interestingly, and in contrast to evidence suggesting that RCTs tend to overestimate outcomes in lung cancer by $18 \%$ versus real-world studies [25], clinical outcomes with afatinib in some real-world studies in Asian patients appeared to be better than those seen in afatinib RCTs. For example, PFS in real-world studies conducted in South Korea [30] and in Japan [37] demonstrated a median PFS of 19.1 and 17.8 months, respectively, with first-line afatinib, whereas median PFS ranged from 11.0 to 13.7 months with afatinib in the LUX-Lung 3, 6 , and 7 RCTs [18-20].

Also noteworthy are findings from the global real-world GioTag study, in which TTF and OS were longer in Asian patients than in the overall global study population of EGFR mutationpositive NSCLC patients who received sequential treatment with afatinib followed by osimertinib after the development of the 
Table 2 Real-world studies conducted in Asia comparing afatinib with first-generation EGFR TKIs or other relevant treatments in EGFR mutation-positive NSCLC: summary of results for subgroups with uncommon EGFR mutations and brain metastases at baseline

\begin{tabular}{|c|c|c|c|c|}
\hline Study & Treatment & Patients $(n)$ & Clinical outcome (months) & $p$ value $^{\mathrm{a}}$ \\
\hline \multicolumn{5}{|c|}{ Subgroup with uncommon EGFR mutations ${ }^{\text {b }}$} \\
\hline \multicolumn{5}{|l|}{ South Korea } \\
\hline \multirow[t]{3}{*}{ Kim et al. [30] } & Afatinib & 14 & PFS: not reached & 0.06 \\
\hline & Gefitinib & 12 & PFS: 5.0 & \\
\hline & Erlotinib & 5 & PFS: 6.1 & \\
\hline \multicolumn{5}{|l|}{ Taiwan } \\
\hline \multirow[t]{3}{*}{ Lin et al. [32] } & Afatinib & 17 & OS: 38.6 & 0.81 \\
\hline & Gefitinib & 10 & OS: not reached & \\
\hline & Erlotinib & 4 & OS: 33.6 & \\
\hline \multirow[t]{3}{*}{ Shen et al. [44] } & Afatinib & 24 & PFS: $11.0^{\mathrm{c}}$ & 0.03 \\
\hline & Gefitinib & 32 (combined) & PFS: 3.6 (combined) & \\
\hline & Erlotinib & & & \\
\hline \multirow[t]{3}{*}{ Tu et al. [34] } & Afatinib & 23 & PFS: 19.7 & 0.506 \\
\hline & Gefitinib & 14 & PFS: 7.0 & \\
\hline & Erlotinib & 12 & PFS: 7.0 & \\
\hline \multirow[t]{3}{*}{ Yang et al. [74] } & Afatinib & 17 & PFS: 5.5 & 0.3025 \\
\hline & Gefitinib & 31 & PFS: 6.2 & \\
\hline & Erlotinib & 9 & PFS: 9.0 & \\
\hline \multicolumn{5}{|c|}{ Subgroup with brain metastases at baseline } \\
\hline \multicolumn{5}{|l|}{ South Korea } \\
\hline \multirow[t]{3}{*}{ Kim et al. ${ }^{\mathrm{d}}[30]$} & Afatinib only & 71 (combined) & PFS: 15.7 & 0.21 \\
\hline & Afatinib + WBRT & & PFS: 11.5 & \\
\hline & Afatinib + GKS & & PFS: 15.6 & \\
\hline \multicolumn{5}{|l|}{ Taiwan } \\
\hline \multirow[t]{3}{*}{ Kuan et al. [31] } & Afatinib & 17 & PFS & HR: $0.42(95 \% \text { CI } 0.16-1.05)^{\mathrm{e}}$ \\
\hline & Gefitinib & 60 & & \\
\hline & Erlotinib & 11 & & \\
\hline \multirow[t]{3}{*}{ Su et al. [54] } & Afatinib & $N R^{f}$ & PFS: 8.2 & 0.34 \\
\hline & Gefitinib & & PFS: 10.5 & \\
\hline & Erlotinib & & PFS: 10.4 & \\
\hline
\end{tabular}


Table 2 continued

\begin{tabular}{lllll}
\hline Study & Treatment & Patients $(\boldsymbol{n})$ & Clinical outcome (months) & $\boldsymbol{p}_{\text {value }}$ \\
\hline \multirow{2}{*}{ Tu et al. [34] } & Afatinib & 22 & PFS: 9.9 & 0.367 \\
& Gefitinib & 34 & PFS: 8.9 & \\
& Erlotinib & 17 & PFS: 7.2 & \\
\hline
\end{tabular}

$C I$ confidence interval, EGFR epidermal growth factor receptor, GKS gamma knife surgery, $H R$ hazard ratio, NR not reported, NSCLC non-small cell lung cancer, $O S$ overall survival, PFS progression-free survival, TKIs tyrosine kinase inhibitors, WBRT whole brain radiotherapy

${ }^{a}$ Afatinib versus comparator(s)

b EGFR mutations other than Del19 or L858R

c Excluded patients with EGFR exon 20 insertions

${ }^{\mathrm{d}}$ Data for gefitinib and erlotinib not reported

${ }^{\mathrm{e}} \mathrm{HR}$ for afatinib versus gefitinib

${ }^{f}$ Overall, 115, 116, and 75 patients received afatinib, gefitinib, and erlotinib, respectively; however, the number of patients with brain metastases at baseline was not reported

T790M mutation [40-42]. Median TTF was 37.1 months (90\% CI 28.1-40.3) in the Asian subgroup $(n=50)$ compared with 27.7 months (90\% CI 26.7-29.9) in the overall population $(n=204)$, while median OS was 44.8 months (90\% CI 37.0-57.8) in Asian patients and 37.6 months (90\% CI 35.5-41.3) in the overall population [42]. Similarly, in a subgroup analysis of 169 GioTag patients, who received an afatinib starting dose of $40 \mathrm{mg}$ /day, median TTF was 27.6 months (90\% CI 26.3-31.3) overall but 46.7 months (90\% CI 28.4-not reached) in Asian patients [43].

\section{Effectiveness in Real-World Populations Often Excluded from Clinical Trials}

Patients with poor prognostic factors, such as those with uncommon EGFR mutations, baseline brain metastases, elderly patients, and Eastern Cooperative Oncology Group performance status (ECOG PS) $\geq 2$, are often excluded from RCTs. Hence, there are limited prospective, clinical trial data with afatinib for such patients, and real-world studies are particularly valuable. This section focuses on real-world studies in Asian patients with these poor prognostic factors, and Table 2 provides an overview of studies comparing afatinib with first-generation EGFR TKIs in two of these subgroups, i.e., patients with uncommon EGFR mutations and those with brain metastases.

\section{Patients with Uncommon Mutations}

Several real-world studies conducted in Asia have indicated that afatinib has similar activity against certain uncommon mutations as it has against tumors harboring common mutations, and may confer superior outcomes compared with first-generation EGFR TKIs in this setting (Table 2). In a retrospective analysis of 56 patients with uncommon EGFR mutations in Taiwan who were treated with EGFR TKIs, ORRs were $62.5 \%$ with afatinib compared with $50 \%$ for gefitinib or erlotinib $(p=0.35)$ [44]. Median PFS in the respective treatment groups was 11.0 versus 3.6 months $(p=0.03)$ after exclusion of 5 patients with exon 20 insertions, which are generally considered resistant to EGFR TKIs. In patients with G719X, S7681, or L861Q mutations, median PFS was 18.3 months with afatinib compared with 2.6 months with firstgeneration EGFR TKIs $(p=0.012)$. A similar retrospective analysis of 49 patients with uncommon EGFR mutations in Taiwan demonstrated a median PFS of 19.7 months with afatinib compared with a median PFS of 7.0 months for both gefitinib and erlotinib, although the difference was not significant 
( $p=0.506)$ [34]. In contrast, a retrospective analysis of 57 Taiwanese patients with uncommon EGFR mutations found no significant differences in median PFS $(5.5,6.2,9.0$ months, $p=0.3025)$ or OS $(20.5,16.1,12.1$ months, $p=0.9116)$ between patients treated with firstline afatinib, gefitinib, or erlotinib, respectively [45]. Another comparative analysis from Taiwan in 31 patients harboring uncommon EGFR mutations found no significant differences between these three EGFR TKIs in OS [32]. Also in Taiwan, a small retrospective analysis of 7 patients with L747P or L747S substitutions in exon 19 reported that 5 patients who received afatinib had an ORR of $80 \%$ and median PFS of 12.0 months, whereas there were no responses in the two patients who received gefitinib/erlotinib and median PFS was 0.9 months [46]. Further, a South Korean analysis of 467 patients with a median follow-up of 17.7 months showed that, in the subgroup of 31 patients with uncommon EGFR mutations, afatinib recipients had a much longer median PFS (not reached) than patients treated with gefitinib (5.0 months) or erlotinib (6.1 months), although the difference did not achieve statistical significance $(p=0.06)$ as the sample size was small [30].

In a real-world analysis of 85 patients who received afatinib in Malaysia, only 6 patients (7.1\%) had uncommon or complex mutations, and median PFS in this small subgroup was generally similar to that in patients harboring Exon 21 L858R point mutations but shorter than that for patients with exon 19 deletion (9.0 vs. 8.7 vs. 16.0 months) [35]. Also of interest, in an analysis of a broad population of 479 Asian patients who were treated with afatinib, including 67 patients with uncommon EGFR mutations, median PFS was 12.6 months in the subgroup with uncommon mutations compared with 9.1 months for those with common mutations, but the difference was not significant [47]. Although this was a prospective Phase $3 \mathrm{~b}$ trial, it was conducted in a setting similar to real-world practice. A pooled analysis of data from this Phase 3b Asian study and a German non-interventional study also showed that afatinib was active against uncommon EGFR mutations, including L861Q, S7681, or G719X
[48], further adding to the evidence supporting the real-world effectiveness of afatinib in patients with uncommon EGFR mutations.

\section{Patients with Brain Metastases}

Preclinical and clinical trial evidence indicates that afatinib has activity in patients with baseline brain metastases and may protect against CNS spread of the disease [49-52]. However, these studies are limited by small numbers of patients and do not include patients with active brain metastases. Therefore, it is also important to consider real-world data with afatinib in EGFR mutation-positive NSCLC patients with brain metastases. Table 2 provides an overview of studies comparing afatinib with first-generation EGFR TKIs in Asian patients with brain metastases at baseline.

Although the global real-world GioTag study did not compare the activity of afatinib specifically in Asian patients with or without brain metastases at baseline, it did compare its activity in patients with or without brain metastases $[40,42]$. With respect to the latter, median TTF with sequential afatinib and osimertinib was 22.2 months (90\% CI 16.8-29.9) for patients with brain metastases at baseline compared with 28.1 months (90\% CI 27.0-30.3) for those without.

In a Taiwanese study, 82 of 259 afatinibtreated patients with EGFR mutation-positive NSCLC had brain metastases at baseline [53]. Although median OS was shorter among patients with versus those without brain metastases (33.8 months vs. not reached, $p=0.005)$, ORR was generally similar $(63.4 \%$ vs. $72.3 \%$ ). In a comparative study of 422 patients with EGFR mutation-positive NSCLC in Taiwan, findings of a subgroup analysis in 49 patients with brain metastases at baseline showed a median PFS of 9.9 months with afatinib, 8.9 months with gefitinib, and 7.2 months with erlotinib, although the difference was not significant (Table 2) [34]. A similar analysis conducted in Taiwan also showed no significant difference in PFS $(p=0.34)$ or OS $(p=0.46)$ among patients with brain metastases receiving first-line afatinib, gefitinib, or erlotinib [54]. A 
comparative real-world analysis of 88 Taiwanese patients with brain metastases at baseline showed a trend towards a reduction in risk among patients treated with afatinib compared with gefitinib [31] (Table 2). Other real-world data from Taiwan in a small patient population $(n=11)$ showed that afatinib was associated with an ORR of $82 \%$ and a complete cranial response rate of $64 \%$ [55].

The results of a study conducted in Singapore, in which 42 of 125 patients with EGFR mutation-positive NSCLC patients had brain metastases at baseline, showed that median PFS was similar between patients with brain metastases who started on afatinib $40 \mathrm{mg} /$ day and afatinib-treated patients without brain metastases (13.3 vs. 15.0 months, hazard ratio [HR] $0.79,95 \%$ CI $0.34-1.80$ ) [56]. Analysis of data from a cohort of 85 afatinib recipients in Malaysia, which included 25 patients with brain metastases at baseline, also showed no significant difference in median PFS between those with and those without brain metastases (13.5 vs. 14.3 months, HR 0.67 , 95\% CI 0.34-1.27, $p=0.209$ for univariate analysis) [35]. Furthermore, a study conducted in South Korea $(n=165)$, in which $43 \%$ of patients $(n=71)$ had brain metastases at baseline, found no significant differences in median PFS between patients with brain metastases who were treated with afatinib alone, afatinib plus whole brain radiotherapy, or afatinib plus gamma knife surgery (Table 2) [57]. Regular MRI imaging showed that patients treated with afatinib alone had a brain metastases response rate of $76 \%$, indicating a high level of intracranial activity.

\section{Elderly Patients}

Despite the fact that patients diagnosed with EGFR mutation-positive NSCLC are generally elderly ( $\geq 65$ years of age) [58], these patients are often under-represented in RCTs; therefore, real-world data on the effectiveness of afatinib in this patient population are of particular value. In the real-world, global GioTag study with sequential afatinib and osimertinib ( $\sim 25 \%$ Asian patients), TTF was similar in patients aged $<65$ years and those aged $\geq 65$ years $\quad[28.7$ months $\quad(90 \% \quad$ CI 26.8-30.0) vs. 27.3 months (90\% CI 20.4-31.3)] $[40,42]$.

Similar findings were reported in another real-world global study (RealGiDo) with afatinib in EGFR mutation-positive NSCLC, which included a total of 228 patients (43.9\% Asian) [59]. In this analysis, median TTF and time to progression (TTP) were consistent in patients aged $<75$ years and those aged $\geq 75$ years [median TTF was 17.8 vs. 24.9 months $(p=0.51)$, respectively, and median TTP was 20.5 vs. 25.7 months $(p=0.24)$, respectively]; importantly, age had no effect on the afatinib safety profile. In a retrospective analysis of 448 Taiwanese patients with EGFR mutation-positive NSCLC patients treated with afatinib or firstgeneration EGFR TKIs, afatinib was associated with significantly longer PFS than gefitinib in subgroups aged $<65$ years (HR $0.52,95 \%$ CI $0.30-0.88$ ) and $\geq 65$ years (HR $0.47,95 \%$ CI 0.23-0.96) [31]. Together, these data indicate that advanced age should not preclude use of afatinib.

\section{Patients with ECOG PS $\geq 2$}

Patients with ECOG PS $\geq 2$ generally have a less favorable prognosis than those with ECOG PS of 0 or 1 , and are often excluded from RCTs, limiting the available evidence of treatment efficacy in these patients. Real-world data from the global GioTag and RealGiDo studies (both of which included a significant proportion of Asian patients) provide some insight into the effectiveness of afatinib in patients with EGFR mutation-positive NSCLC and poor performance status.

In the GioTag study with sequential afatinib and osimertinib, TTF was longer in patients with ECOG PS $\leq 1(n=152)$ than in those with ECOG PS $\geq 2 \quad(n=31) \quad$ [30.0 months $(90 \%$ CI 28.1-31.7) vs. 22.2 months (90\% CI 16.0-26.5)] $[40,42]$. Similarly, in the RealGiDo study, both median TTF and median TTP were significantly longer in patients with ECOG $\leq 1$ than in those with ECOG PS $\geq 2$ (20.0 vs. 11.3 months and 22.4 vs. 12.2 months, respectively; $p$ values not reported) [59]. In contrast, in a cohort of 85 
afatinib-treated patients in Malaysia, median PFS was numerically longer among those with ECOG PS $\geq 2$ than in patients with ECOG PS $\leq 1$ (15.9 vs. 13.8 months) (HR 0.86, 95\% CI $0.39-1.90, p=0.703$ ) [35]. These data suggest that afatinib provides real-world clinical benefit in patients with ECOG PS $\geq 2$.

\section{REAL-WORLD EVIDENCE FOR THE TOLERABILITY AND SAFETY OF AFATINIB}

Based on data from RCTs, the tolerability profile of EGFR TKIs is predictable and usually manageable with supportive care and/or dose reductions $[60,61]$. Typically $\leq 10 \%$ of patients in Phase 3 clinical trials discontinued therapy because of adverse events [9-12, 14-19]. Encouragingly, discontinuation rates appear consistent in real-world clinical practice. Among 541 patients with EGFR mutation-positive NSCLC who received afatinib in an observational study in Asia, treatment-related adverse events leading to discontinuation of afatinib occurred in $3.1 \%$ of patients [62]. In a study in South Korea, $6.1 \%$ of 165 patients who received first-line afatinib discontinued treatment due to adverse events [30]. These values are consistent with those reported in the RCTs of afatinib [18-20]. The tolerability profile of afatinib in the real-world setting also reflects that seen in prospective clinical trials, and no new safety signals have been reported in realworld studies in Asian patients with EGFR mutation-positive NSCLC. As seen in RCTs, the most frequently reported adverse events in the real-world setting in Asian patients were primarily gastrointestinal and dermatologic. For example, in a large $(n=467)$, comparative analysis conducted in South Korea, rash/acne, stomatitis, paronychia, diarrhea, dry skin, and pruritus were the most frequently reported adverse events with afatinib, gefitinib, and erlotinib [30]. Most adverse events were grade 1 or 2 , whereas grade 3 or 4 adverse events were uncommon but more frequently reported with afatinib than the first-generation EGFR TKIs.

\section{REAL-WORLD PRESCRIBING PRACTICES FOR AFATINIB}

\section{Tolerability-Guided Dose Modification}

Well-designed prospective clinical trials with afatinib in EGFR mutation-positive patients with NSCLC have shown that tolerability-guided dose modification can reduce the incidence of adverse events without adversely impacting efficacy [18-20]. Results from the real-world RealGido study confirmed this in a broad patient population that included a large proportion of Asian patients (44\%) [59]. In the overall study population of 228 patients, 31\% received a modified afatinib dose of $\leq 30 \mathrm{mg} /$ day. Most dose reductions occurred within the first 6 months of treatment and were related to adverse events. Importantly, clinical efficacy (TTP or TTF) among patients who received a modified starting dose of afatinib was similar to that for the overall real-world population [59].

Results from the RealGido study are supported by those from an analysis of 140 patients in Taiwan, in which there was no significant difference in clinical outcomes (response, PFS, and adverse events) between patients who received afatinib $40 \mathrm{mg} /$ day and those who received afatinib $<40 \mathrm{mg} /$ day in the first 6 months [36]. While these data support the clinical trial evidence, and demonstrate that tolerability-guided dose reductions do not impact efficacy, a retrospective study in 245 patients in Taiwan suggested that reducing the afatinib dose to $<20 \mathrm{mg} /$ day may be associated with poorer outcomes [32].

\section{Sequencing}

Regardless of which EGFR TKI is used in the first-line setting, the development of resistance is inevitable, making the choice of subsequent treatments an important consideration $[63,64]$. Optimal treatment sequencing of EGFR TKIs is an area of ongoing discussion, with clonal evolution of tumors being an increasingly important consideration [65]. 
The T790M mutation is the most common resistance mechanism to first- and second-generation EGFR TKIs, reported in 50\% of Asian patients after first-line afatinib therapy, with C797S, BRAF V600E, and MET amplifications also detected but at much lower prevalences $[66,67]$. However, resistance mechanisms and targeted treatment options after first-line osimertinib therapy are not well defined [68-71]. Consequently, optimal treatment sequencing of EGFR TKIs is an area of active discussion [63, 72], with some studies assessing the benefit of using first- or second-generation EGFR TKIs as first-line therapy, reserving osimertinib as second-line therapy. Indeed, this discussion may be particularly relevant to Asian populations following the limited OS benefit seen in this subgroup with first-line osimertinib in the Phase 3 FLAURA trial, in which osimertinib was no more effective than first-generation EGFR TKIs (HR 1.00, 95\% CI 0.75-1.32 for OS) [21].

In this regard, findings of the real-world GioTag study with sequential afatinib and osimertinib are noteworthy. The GioTag study demonstrated encouraging TTF and OS results, particularly in Asian patients with EGFR mutation-positive NSCLC [42]. These data are also supported by those from a retrospective Japanese study that demonstrated better outcomes when osimertinib was administered after afatinib versus after gefitinib/erlotinib [73]. The study included 111 patients with the T790M mutation treated with osimertinib, and showed that ORR was $82.9 \%$ for the sequence of afatinib followed by osimertinib compared with $53.9 \%$ for first-generation EGFR TKI followed by osimertinib $(p=0.0065)$. Follow-up is ongoing, but available data indicate a numerically longer PFS for the afatinib-treated patients (15.7 vs. 8.9 months, $p=0.195$ ).

\section{CONCLUSION}

This review highlights the wealth of real-world evidence supporting the effectiveness and tolerability of afatinib in Asian patients with EGFR mutation-positive NSCLC. Data on the effectiveness of afatinib in routine clinical practice complement results of well-designed prospective clinical trials demonstrating the efficacy of afatinib in Asian patients, and point towards more favorable outcomes with afatinib versus first-generation EGFR TKIs in real-world patient populations. Moreover, various subgroup analyses with afatinib in the real-world setting demonstrated effectiveness in patients often under-represented in or excluded from prospective clinical trials, such as those with uncommon EGFR mutations, brain metastases at baseline, elderly patients, and those with ECOG PS $\geq 2$.

In general, tolerability data from real-world studies in Asian patients reflect those reported in prospective clinical trials with afatinib. In addition, findings of the real-world RealGido study, which included 44\% Asian patients, confirmed that prospective clinical trial data showing tolerability-guided afatinib dose modifications can reduce the incidence of adverse events without adversely affecting clinical outcomes.

An area of ongoing discussion and a need for further research is that of optimal treatment sequences for patients with EGFR mutationpositive NSCLC. Interestingly, the global realworld GioTag study, in which Asian patients represented about one-quarter of the study population, showed encouraging results for the overall study population, and TTF was significantly longer in Asian than in non-Asian patients treated with sequential afatinib and osimertinib. Together, and in contrast to the limited real-world data available for some other EGFR TKIs [27], this wealth of real-world evidence supports the use of afatinib as a first-line therapy in Asian patients with EGFR mutationpositive NSCLC.

\section{ACKNOWLEDGEMENTS}

Funding. This work and the journal's Rapid Service and Open Access fees were funded by Boehringer Ingelheim.

Medical Writing Assistance. Medical writing assistance was provided by Greg Plosker, 
contracted on behalf of Ashfield Medcomms, an Ashfield Health Company, and funded by Boehringer Ingelheim.

Authorship. All named authors meet the International Committee of Medical Journal Editors (ICMJE) criteria for authorship for this article, take responsibility for the integrity of the work as a whole, and have given their approval for this version to be published.

Disclosures. Shun Lu reports research grants from AstraZeneca, Hutchison, BMS, Heng Rui, and Roche; speaker fees from Astra Zeneca, Roche, and Hansoh; advisory/consultancy fees from Astra Zeneca, Boehringer Ingelheim, Hutchison MediPharma, Simcere, ZaiLab, GenomiCare and Roche, outside the submitted work. Jin-Yuan Shih has served as an advisory board member from AstraZeneca, Roche, Boehringer Ingelheim, Novartis, Merck Sharp \& Dohme, Ono Pharmaceutical, Chugai, and Bristol-Myers Squibb and received a research grant from Roche, speaking honoraria from AstraZeneca, Roche, Boehringer Ingelheim, Eli Lilly, Pfizer, Novartis, Merck Sharp \& Dohme, Ono Pharmaceutical, Chugai, and Bristol-Myers Squibb, and expenses for travel and accommodations from Roche, Boehringer Ingelheim, Pfizer, Merck Sharp \& Dohme, and Bristol-Myers Squibb. Tae-Won Jang reports research grants from Boehringer Ingelheim and Ono, and honoraria and fees for lectures and/or advisory board meetings from AstraZeneca, Boehringer Ingelheim, Bristol-Myers Squibb, Roche, Ono and Pfizer. Chong-Kin Liam reports research grants from AstraZeneca and Boehringer Ingelheim, and honoraria and fees for lectures and advisory board meetings from AstraZeneca, Boehringer Ingelheim, Merck Sharp \& Dohme, and Novartis. Yongfeng Yu reports lecture fees from AstraZeneca, Boehringer Ingelheim and BMS.

Compliance with Ethics Guidelines. This article is based on previously conducted studies and does not contain any studies with human participants or animals performed by any of the authors.
Data Availability. Data sharing is not applicable to this article as no datasets were generated or analyzed during the current study.

Open Access. This article is licensed under a Creative Commons Attribution-NonCommercial 4.0 International License, which permits any non-commercial use, sharing, adaptation, distribution and reproduction in any medium or format, as long as you give appropriate credit to the original author(s) and the source, provide a link to the Creative Commons licence, and indicate if changes were made. The images or other third party material in this article are included in the article's Creative Commons licence, unless indicated otherwise in a credit line to the material. If material is not included in the article's Creative Commons licence and your intended use is not permitted by statutory regulation or exceeds the permitted use, you will need to obtain permission directly from the copyright holder. To view a copy of this licence, visit http:// creativecommons.org/licenses/by-nc/4.0/.

\section{REFERENCES}

1. Han B, Tjulandin S, Hagiwara K, et al. EGFR mutation prevalence in Asia-Pacific and Russian patients with advanced NSCLC of adenocarcinoma and non-adenocarcinoma histology: The IGNITE study. Lung Cancer. 2017;113:37-44. https://doi.org/10. 1016/j.lungcan.2017.08.021.

2. Shi Y, Au JS, Thongprasert S, et al. A prospective, molecular epidemiology study of EGFR mutations in Asian patients with advanced non-small-cell lung cancer of adenocarcinoma histology (PIONEER). J Thorac Oncol. 2014;9(2):154-62. https:// doi.org/10.1097/jto.0000000000000033.

3. Wang LY, Cui JJ, Guo AX, Yin JY. Clinical efficacy and safety of afatinib in the treatment of non-smallcell lung cancer in Chinese patients. Onco Targets Ther. 2018;11:529-38. https://doi.org/10.2147/ott. S136579.

4. Zhang YL, Yuan JQ, Wang KF, et al. The prevalence of EGFR mutation in patients with non-small cell lung cancer: a systematic review and meta-analysis. Oncotarget. 2016;7(48):78985-93. https://doi.org/ 10.18632/oncotarget.12587. 
5. Zhou J, Song XB, He H, Zhou Y, Lu XJ, Ying BW. Prevalence and clinical profile of EGFR mutation in non-small-cell lung carcinoma patients in Southwest China. Asian Pac J Cancer Prev. 2016;17(3): 965-71. https://doi.org/10.7314/apjcp.2016.17.3. 965.

6. Hanna N, Johnson D, Temin S, et al. Systemic therapy for stage IV non-small-cell lung cancer: American Society of Clinical Oncology clinical practice guideline update. J Clin Oncol. 2017;35(30):3484-515. https://doi.org/10.1200/jco. 2017.74.6065.

7. Planchard D, Popat S, Kerr K, et al. Metastatic nonsmall cell lung cancer: ESMO Clinical Practice Guidelines for diagnosis, treatment and follow-up. Ann Oncol. 2018;29(Suppl 4):iv192-237. https:// doi.org/10.1093/annonc/mdy275.

8. Wu YL, Planchard D, Lu S, et al. Pan-Asian adapted Clinical Practice Guidelines for the management of patients with metastatic non-small-cell lung cancer: a CSCO-ESMO initiative endorsed by JSMO, KSMO, MOS, SSO and TOS. Ann Oncol. 2019;30(2): 171-210. https://doi.org/10.1093/annonc/mdy554.

9. Zhou C, Wu YL, Chen G, et al. Erlotinib versus chemotherapy as first-line treatment for patients with advanced EGFR mutation-positive non-smallcell lung cancer (OPTIMAL, CTONG-0802): a multicentre, open-label, randomised, phase 3 study. Lancet Oncol. 2011;12(8):735-42. https://doi.org/ 10.1016/s1470-2045(11)70184-x.

10. Rosell R, Carcereny E, Gervais R, et al. Erlotinib versus standard chemotherapy as first-line treatment for European patients with advanced EGFR mutation-positive non-small-cell lung cancer (EURTAC): a multicentre, open-label, randomised phase 3 trial. Lancet Oncol. 2012;13(3):239-46. https://doi.org/10.1016/s1470-2045(11)70393-x.

11. Wu YL, Zhou C, Liam CK, et al. First-line erlotinib versus gemcitabine/cisplatin in patients with advanced EGFR mutation-positive non-small-cell lung cancer: analyses from the phase III, randomized, open-label, ENSURE study. Ann Oncol. 2015;26(9):1883-9. https://doi.org/10.1093/ annonc/mdv270.

12. Mok TS, Wu YL, Thongprasert S, et al. Gefitinib or carboplatin-paclitaxel in pulmonary adenocarcinoma. N Engl J Med. 2009;361(10):947-57. https:// doi.org/10.1056/NEJMoa0810699.

13. Maemondo $\mathrm{M}$, Inoue $\mathrm{A}$, Kobayashi $\mathrm{K}$, et al. Gefitinib or chemotherapy for non-small-cell lung cancer with mutated EGFR. N Engl J Med. 2010;362(25):2380-8. https://doi.org/10.1056/ NEJMoa0909530.
14. Mitsudomi T, Morita S, Yatabe Y, et al. Gefitinib versus cisplatin plus docetaxel in patients with nonsmall-cell lung cancer harbouring mutations of the epidermal growth factor receptor (WJTOG3405): an open label, randomised phase 3 trial. Lancet Oncol. 2010;11(2):121-8. https://doi.org/10.1016/s14702045(09)70364-X.

15. Shi YK, Wang L, Han BH, et al. First-line icotinib versus cisplatin/pemetrexed plus pemetrexed maintenance therapy for patients with advanced EGFR mutation-positive lung adenocarcinoma (CONVINCE): a phase 3, open-label, randomized study. Ann Oncol. 2017;28(10):2443-50. https:// doi.org/10.1093/annonc/mdx359.

16. Wu YL, Cheng Y, Zhou X, et al. Dacomitinib versus gefitinib as first-line treatment for patients with EGFR-mutation-positive non-small-cell lung cancer (ARCHER 1050): a randomised, open-label, phase 3 trial. Lancet Oncol. 2017;18(11):1454-66. https:// doi.org/10.1016/s1470-2045(17)30608-3.

17. Soria JC, Ohe Y, Vansteenkiste J, et al. Osimertinib in untreated EGFR-mutated advanced non-smallcell lung cancer. N Engl J Med. 2018;378(2):113-25. https://doi.org/10.1056/NEJMoa1713137.

18. Sequist LV, Yang JC, Yamamoto N, et al. Phase III study of afatinib or cisplatin plus pemetrexed in patients with metastatic lung adenocarcinoma with EGFR mutations. J Clin Oncol. 2013;31(27): 3327-34. https://doi.org/10.1200/jco.2012.44. 2806.

19. Wu YL, Zhou C, Hu CP, et al. Afatinib versus cisplatin plus gemcitabine for first-line treatment of Asian patients with advanced non-small-cell lung cancer harbouring EGFR mutations (LUX-Lung 6): an open-label, randomised phase 3 trial. Lancet Oncol. 2014;15(2):213-22. https://doi.org/10.1016/ s1470-2045(13)70604-1.

20. Park K, Tan EH, O'Byrne $\mathrm{K}$, et al. Afatinib versus gefitinib as first-line treatment of patients with EGFR mutation-positive non-small-cell lung cancer (LUX-Lung 7): a phase 2B, open-label, randomised controlled trial. Lancet Oncol. 2016;17(5):577-89. https://doi.org/10.1016/s1470-2045(16)30033-X.

21. Ramalingam SS, Vansteenkiste J, Planchard D, et al. Overall survival with osimertinib in untreated, EGFR-mutated advanced NSCLC. N Engl J Med. 2020;382(1):41-50. https://doi.org/10.1056/ NEJMoa1913662.

22. Khozin S, Blumenthal GM, Pazdur R. Real-world data for clinical evidence generation in oncology. J Natl Cancer Inst. 2017. https://doi.org/10.1093/ jnci/djx187. 
23. Roche N, Reddel H, Martin R, et al. Quality standards for real-world research. Focus on observational database studies of comparative effectiveness. Ann Am Thorac Soc. 2014;11(Suppl 2):S99-104. https://doi.org/10.1513/AnnalsATS. 201309-300RM.

24. Sherman RE, Anderson SA, Dal Pan GJ, et al. Realworld evidence-what is it and what can it tell us? N Engl J Med. 2016;375(23):2293-7. https://doi. org/10.1056/NEJMsb1609216.

25. Lakdawalla DN, Shafrin J, Hou N, et al. Predicting real-world effectiveness of cancer therapies using overall survival and progression-free survival from clinical trials: empirical evidence for the ASCO value framework. Value Health. 2017;20(7):866-75. https://doi.org/10.1016/j.jval.2017.04.003.

26. Chinese Society of Clinical Oncology (CSCO). China Real World Research Guidelines 2018. https://wenku.baidu.com/view/ 6bed76a5b9f67c1cfad6195f312b3169a451ea05. html Accessed 13 Jan 2020

27. Wang S, Li J. Second-generation EGFR and ErbB tyrosine kinase inhibitors as first-line treatments for non-small cell lung cancer. Onco Targets Ther. 2019;12:6535-48. https://doi.org/10.2147/ott. S198945.

28. Fujiwara A, Yoshida M, Fujimoto H, et al. A retrospective comparison of the clinical efficacy of gefitinib, erlotinib, and afatinib in Japanese patients with non-small cell lung cancer. Oncol Res. 2018;26(7):1031-6. https://doi.org/10.3727/ $096504018 \times 15151523767752$.

29. Ito K, Murotani K, Kubo A, et al. Comparative analysis of overall survival using propensity score between first- and second-generation EGFR-TKI: Real world data of 1354 patients with EGFR mutant NSCLC. Ann Oncol. 2018;29:viii526-7. https://doi. org/10.1093/annonc/mdy292.077.

30. Kim Y, Lee SH, Ahn JS, Ahn MJ, Park K, Sun JM. Efficacy and safety of afatinib for EGFR-mutant non-small cell lung cancer, compared with gefitinib or erlotinib. Cancer Res Treat. 2019;51(2):502-9. https://doi.org/10.4143/crt.2018.117.

31. Kuan FC, Li SH, Wang CL, Lin MH, Tsai YH, Yang CT. Analysis of progression-free survival of first-line tyrosine kinase inhibitors in patients with nonsmall cell lung cancer harboring leu858Arg or exon 19 deletions. Oncotarget. 2017;8(1):1343-53. https://doi.org/10.18632/oncotarget.13815.

32. Lin YT, Chen JS, Liao WY, et al. Clinical outcomes and secondary epidermal growth factor receptor (EGFR) T790M mutation among first-line gefitinib, erlotinib and afatinib-treated non-small cell lung cancer patients with activating EGFR mutations. Int J Cancer. 2019;144(11):2887-96. https://doi.org/10. 1002/ijc.32025.

33. Su VYF, Yang KY, Chen YM. The real-world efficacy of first-line tyrosine kinase inhibitors in Asian patients with EGFR mutation non-small cell lung cancer [abstract no. AO047]. Respirology. 2018;23(Suppl 2):21-2.

34. Tu CY, Chen CM, Liao WC, et al. Comparison of the effects of the three major tyrosine kinase inhibitors as first-line therapy for non-small-cell lung cancer harboring epidermal growth factor receptor mutations. Oncotarget. 2018;9(36):24237-47. https://doi.org/10.18632/oncotarget.24386.

35. Ho GF, Chai CS, Alip A, et al. Real-world experience of first-line afatinib in patients with EGFR-mutant advanced NSCLC: a multicenter observational study. BMC Cancer. 2019;19(1):896. https://doi. org/10.1186/s12885-019-6107-1.

36. Liang SK, Hsieh MS, Lee MR, Keng LT, Ko JC, Shih JY. Real-world experience of afatinib as a first-line therapy for advanced EGFR mutation-positive lung adenocarcinoma. Oncotarget. 2017;8(52): 90430-43. https://doi.org/10.18632/oncotarget. 19563.

37. Tanaka $\mathrm{H}$, Taima $\mathrm{K}$, Itoga $\mathrm{M}$, et al. Real-world study of afatinib in first-line or re-challenge settings for patients with EGFR mutant non-small cell lung cancer. Med Oncol. 2019;36(6):57. https://doi.org/ 10.1007/s12032-019-1278-9.

38. Wang S, Xing P, Yang K, et al. Efficacy and safety of afatinib in a Chinese population with advanced lung adenocarcinoma with sensitive EGFR mutations. Thorac Cancer. 2019;10(6):1461-8. https:// doi.org/10.1111/1759-7714.13095.

39. Li Y, Wang X, Wang L, et al. Afatinib in the treatment of advanced NSCLC with EGFR mutation: An observational real-world study. J Clin Oncol. 2019;37(Suppl 15):e20518. https://doi.org/10.1200/ JCO.2019.37.15_suppl.e20518.

40. Hochmair MJ, Morabito A, Hao D, et al. Sequential treatment with afatinib and osimertinib in patients with EGFR mutation-positive non-small-cell lung cancer: an observational study. Future Oncol. 2018;14(27):2861-74. https://doi.org/10.2217/fon2018-0711.

41. Hochmair MJ, Morabito A, Hao D, et al. Sequential afatinib and osimertinib in patients with EGFR mutation-positive non-small-cell lung cancer: updated analysis of the observational GioTag study. Future Oncol. 2019;15(25):2905-14. https://doi. org/10.2217/fon-2019-0346. 
42. Hochmair MJ, Morabito A, Hao D, et al. Sequential afatinib and osimertinib in patients with EGFR mutation-positive non-small-cell lung cancer: final analysis of the GioTag study. Future Oncol. 2020;16(34):2799-808. https://doi.org/10.2217/ fon-2020-0740.

43. Yamamoto N, Mera T, Märten A, Hochmair MJ. Observational study of sequential afatinib and osimertinib in EGFR mutation-positive NSCLC: patients treated with a 40-mg starting dose of afatinib. Adv Ther. 2020;37(2):759-69. https://doi.org/ 10.1007/s12325-019-01187-y.

44. Shen YC, Tseng GC, Tu CY, et al. Comparing the effects of afatinib with gefitinib or Erlotinib in patients with advanced-stage lung adenocarcinoma harboring non-classical epidermal growth factor receptor mutations. Lung Cancer. 2017;110:56-62. https://doi.org/10.1016/j.lungcan.2017.06.007.

45. Tsai MJ, Hung JY, Lee MH, et al. Better ProgressionFree Survival in Elderly Patients with Stage IV Lung Adenocarcinoma Harboring Uncommon Epidermal Growth Factor Receptor Mutations Treated with the First-line Tyrosine Kinase Inhibitors. Cancers (Basel). 2018. https://doi.org/10.3390/ cancers10110434.

46. Liang SK, Ko JC, Yang JC, Shih JY. Afatinib is effective in the treatment of lung adenocarcinoma with uncommon EGFR p.L747P and p.L747S mutations. Lung Cancer. 2019;133:103-9. https:// doi.org/10.1016/j.lungcan.2019.05.019.

47. Wu Y, Tu H, Feng J, et al. P3.01-036 A phase IIIb open-label, single-arm study of afatinib in EGFR TKI-naive patients with EGFRm + NSCLC: an interim analysis. J Thorac Oncol. 2017;12(11): S2214. https://doi.org/10.1016/j.jtho.2017.09. 1477.

48. Brückl W, Laack E, Hoffmann C, Zhou C, Wu Y. P2. 01-79 Afatinib in EGFR mutation-positive $($ EGFRm+) NSCLC harbouring uncommon mutations: experience in real-world clinical practice. J Thorac Oncol. 2019;14(10):S670-1. https://doi. org/10.1016/j.jtho.2019.08.1422.

49. Tamiya A, Tamiya M, Nishihara T, et al. Cerebrospinal fluid penetration rate and efficacy of afatinib in patients with EGFR mutation-positive non-small cell lung cancer with leptomeningeal carcinomatosis: a multicenter prospective study. Anticancer Res. 2017;37(8):4177-82. https://doi. org/10.21873/anticanres.11806.

50. Ballard P, Yates JW, Yang Z, et al. Preclinical comparison of osimertinib with other EGFR-TKIs in EGFR-mutant NSCLC brain metastases models, and early evidence of clinical brain metastases activity.
Clin Cancer Res. 2016;22(20):5130-40. https://doi. org/10.1158/1078-0432.Ccr-16-0399.

51. Zhang SR, Zhu LC, Jiang YP, et al. Efficacy of afatinib, an irreversible ErbB family blocker, in the treatment of intracerebral metastases of non-small cell lung cancer in mice. Acta Pharmacol Sin. 2017;38(2):233-40. https://doi.org/10.1038/aps. 2016.107.

52. Schuler M, Wu YL, Hirsh V, et al. First-line afatinib versus chemotherapy in patients with non-small cell lung cancer and common epidermal growth factor receptor gene mutations and brain metastases. J Thorac Oncol. 2016;11(3):380-90. https:// doi.org/10.1016/j.jtho.2015.11.014.

53. Liang SK, Lee MR, Liao WY, Ho CC, Ko JC, Shih JY. Prognostic factors of afatinib as a first-line therapy for advanced EGFR mutation-positive lung adenocarcinoma: a real-world, large cohort study. Oncotarget. 2018;9(34):23749-60. https://doi.org/10. 18632/oncotarget.25255.

54. Su PL, Wu YL, Chang WY, et al. Preventing and treating brain metastases with three first-line EGFRtyrosine kinase inhibitors in patients with EGFR mutation-positive advanced non-small cell lung cancer. Ther Adv Med Oncol. 2018;10: 1758835918797589 . https://doi.org/10.1177/ 1758835918797589.

55. Li SH, Liu CY, Hsu PC, et al. Response to afatinib in treatment-naïve patients with advanced mutant epidermal growth factor receptor lung adenocarcinoma with brain metastases. Expert Rev Anticancer Ther. 2018;18(1):81-9. https://doi.org/10.1080/ 14737140.2018.1409623.

56. Tan WL, Ng QS, Lim C, et al. Correction to: Influence of afatinib dose on outcomes of advanced EGFR-mutant NSCLC patients with brain metastases. BMC Cancer. 2018;18(1):1288. https://doi. org/10.1186/s12885-018-5215-7.

57. Kim Y, Sun J, Park K, et al. P3.01-023 First-line afatinib for non-small cell lung cancer in real world practice. J Thorac Oncol. 2017;12(11):S2209. https://doi.org/10.1016/j.jtho.2017.09.1464.

58. Wu YL, Sequist LV, Tan EH, et al. Afatinib as firstline treatment of older patients with EGFR mutation-positive non-small-cell lung cancer: subgroup analyses of the LUX-Lung 3, LUX-Lung 6, and LUXLung 7 trials. Clin Lung Cancer. 2018;19(4): e465-79. https://doi.org/10.1016/j.cllc.2018.03. 009.

59. Halmos B, Tan EH, Soo RA, et al. Impact of afatinib dose modification on safety and effectiveness in patients with EGFR mutation-positive advanced NSCLC: Results from a global real-world study 
(RealGiDo). Lung Cancer. 2019;127:103-11. https://doi.org/10.1016/j.lungcan.2018.10.028.

60. Melosky B, Hirsh V. Management of common toxicities in metastatic NSCLC related to anti-lung cancer therapies with EGFR-TKIs. Front Oncol. 2014;4:238. https://doi.org/10.3389/fonc.2014. 00238 .

61. Yang JC, Sequist LV, Zhou C, et al. Effect of dose adjustment on the safety and efficacy of afatinib for EGFR mutation-positive lung adenocarcinoma: post hoc analyses of the randomized LUX-Lung 3 and 6 trials. Ann Oncol. 2016;27(11):2103-10. https:// doi.org/10.1093/annonc/mdw322.

62. Wu Y, Tu H, Feng J, et al. P2.01-99 A phase IIIb open-label study of afatinib in EGFR TKI-naïve patients with EGFR mutation-positive NSCLC: final analysis. J Thorac Oncol. 2019;14(10):S679-80. https://doi.org/10.1016/j.jtho.2019.08.1442.

63. Girard N. Optimizing outcomes in EGFR mutationpositive NSCLC: which tyrosine kinase inhibitor and when? Future Oncol. 2018;14(11):1117-32. https://doi.org/10.2217/fon-2017-0636.

64. Hirsh V. Turning EGFR mutation-positive nonsmall-cell lung cancer into a chronic disease: optimal sequential therapy with EGFR tyrosine kinase inhibitors. Ther Adv Med Oncol. 2018;10: 1758834017753338 . https://doi.org/10.1177/ 1758834017753338 .

65. Kohsaka S, Petronczki M, Solca F, Maemondo M. Tumor clonality and resistance mechanisms in EGFR mutation-positive non-small-cell lung cancer: implications for therapeutic sequencing. Future Oncol. 2019;15(6):637-52. https://doi.org/10.2217/ fon-2018-0736.

66. Wu SG, Liu YN, Tsai MF, et al. The mechanism of acquired resistance to irreversible EGFR tyrosine kinase inhibitor-afatinib in lung adenocarcinoma patients. Oncotarget. 2016;7(11):12404-13. https:// doi.org/10.18632/oncotarget.7189.

67. Tanaka K, Nosaki K, Otsubo K, et al. Acquisition of the T790M resistance mutation during afatinib treatment in EGFR tyrosine kinase inhibitor-naïve patients with non-small cell lung cancer harboring EGFR mutations. Oncotarget. 2017;8(40):68123-30. https://doi.org/10.18632/oncotarget.19243.

68. Yang Z, Yang N, Ou Q, et al. Investigating novel resistance mechanisms to third-generation EGFR tyrosine kinase inhibitor osimertinib in non-small cell lung cancer patients. Clin Cancer Res. 2018;24(13):3097-107. https://doi.org/10.1158/ 1078-0432.Ccr-17-2310.

69. Oxnard GR, Hu Y, Mileham KF, et al. Assessment of resistance mechanisms and clinical implications in patients with EGFR T790M-positive lung cancer and acquired resistance to osimertinib. JAMA Oncol. 2018;4(11):1527-34. https://doi.org/10. 1001/jamaoncol.2018.2969.

70. Ramalingam S, Cheng Y, Zhou C, et al. Mechanisms of acquired resistance to first-line osimertinib: Preliminary data from the phase III FLAURA study. Ann Oncol. 2018;29:Abstract LBA50. https://doi. org/10.1093/annonc/mdy424.063.

71. Ramalingam SS, Yang JC, Lee CK, et al. Osimertinib as first-line treatment of EGFR mutation-positive advanced non-small-cell lung cancer. J Clin Oncol. 2018;36(9):841-9. https://doi.org/10.1200/jco. 2017.74.7576.

72. Girard N. Optimizing outcomes and treatment sequences in EGFR mutation-positive non-smallcell lung cancer: recent updates. Future Oncol. 2019;15(25):2983-97. https://doi.org/10.2217/fon2019-0400.

73. Tamiya M, Tamiya A, Suzuki H, Nakahama K, Taniguchi Y, Kunimasa K. Which is better EGFR-TKI followed by osimertinib between afatinib and gefitinib/erlotinib. Ann Oncol. 2018;29(Suppl 8):viii493-547. https://doi.org/10.1093/annonc/ mdy292.

74. Yang CJ, Tsai MJ, Hung JY. First-line gefitinib, erlotinib, and afatinib provided similar clinical efficacy in patients who had stage IV lung adenocarcinoma harboring rare EGFR mutation in Taiwan. Respirology. 2018;23(Suppl2):293. https://doi. org/10.1111/resp.13420_563 (Abstract no. AP557). 